\title{
Child and family factors associated with child mental health and well-being during COVID-19
}

\author{
Brae Anne McArthur ${ }^{1}$ (D) Nicole Racine $^{1} \cdot$ Sheila McDonald $^{2} \cdot$ Suzanne Tough $^{3} \cdot$ Sheri Madigan $^{1}$
}

Received: 28 May 2021 / Accepted: 16 July 2021 / Published online: 24 July 2021

c) Springer-Verlag GmbH Germany, part of Springer Nature 2021

\begin{abstract}
Understanding the implications of the COVID-19 pandemic on the current generation of youth is critical for post-pandemic recovery planning. This study aimed to identify the most salient child (i.e., connectedness to caregivers, screen time, sleep, physical activity, peer relationships, and recreational activities) and family (i.e., COVID-19 financial impact, maternal depression and anxiety) factors associated with children's mental health and well-being during the COVID-19 pandemic, after controlling for pre-pandemic mental health. This study included 846 mother-child dyads (child age 9-11) from the All Our Families cohort. Mothers reported on the child's pre-pandemic mental health at age 8 (2017-2019) and during COVID-19 (May-July 2020), the family's financial impact due to COVID-19, and maternal depression and anxiety. During COVID-19 (July-August 2020), children reported on their screen time, sleep, physical activity, peer and family relationships, and recreational activities, as well as their happiness, anxiety and depression. After controlling for pre-pandemic anxiety, connectedness to caregivers $(B-0.16 ; 95 \% \mathrm{CI}-0.22$ to -0.09$)$, child sleep $(B-0.11 ; 95 \% \mathrm{CI}-0.19$ to -0.04$)$, and child screen time $(B 0.11 ; 95 \%$ CI $0.04-0.17)$ predicted child COVID-19 anxiety symptoms. After controlling for pre-pandemic depression, connectedness to caregivers $(B-0.26$; $95 \% \mathrm{CI}-0.32$ to -0.21$)$ and screen time $(B 0.09 ; 95 \% \mathrm{CI} 0.02-0.16)$ predicted child COVID-19 depressive symptoms. After controlling for covariates, connectedness to caregivers $(B$ 0.36; $95 \%$ CI 0.28-0.39) predicted child COVID-19 happiness. Fostering parent-child connections and promoting healthy device and sleep habits are critical modifiable factors that warrant attention in post-pandemic mental health recovery planning.
\end{abstract}

Keywords COVID-19 $\cdot$ Child $\cdot$ Mental health $\cdot$ Screen time $\cdot$ Sleep $\cdot$ Parent-child connections

\section{Introduction}

Children have experienced significant life disruptions as a result of the COVID-19 pandemic, including school closures, social distancing, missed milestones, and family stress (e.g., income loss and parent mental illness) [1,2].

Suzanne Tough and Sheri Madigan share senior authorship.

Sheri Madigan

sheri.madigan@ucalgary.ca

Brae Anne McArthur

braeanne.mcarthur@ucalgary.ca

Nicole Racine

nicole.racine2@ucalgary.ca

Sheila McDonald

sheila.mcdonald@albertahealthservices.ca

Suzanne Tough

stough@ucalgary.ca
The potential for the COVID-19 pandemic to have significant consequences for child mental health and well-being has garnered considerable attention from parents, the media, health practitioners, and policy makers, leading many to ask "are the kids alright?" While empirical evidence is beginning to suggest a significant increase in children's mental health symptoms [3-5], few studies have clearly identified the socio-environmental factors associated with children's

1 Department of Psychology, Faculty of Arts, Alberta Children's Hospital Research Institute, University of Calgary, 2500 University Dr. NW., Calgary, AB T2N 1N4, Canada

2 Department of Pediatrics, Cumming School of Medicine, University of Calgary, 2500 University Dr. NW., Calgary, AB T2N 1N4, Canada

3 Department of Pediatrics and Community Health Sciences, Cumming School of Medicine, Alberta Children's Hospital Research Institute, University of Calgary, 2500 University Dr. NW., Calgary, AB T2N 1N4, Canada 
mental health struggles during the COVID-19 pandemic. Thus, research identifying the most salient child and/or family COVID-19-specific predictors of child mental health and well-being, while accounting for pre-pandemic mental health and well-being, has been identified as an urgent research priority $[6,7]$ to adequately inform intervention and recovery efforts.

Child mental health during COVID-19 is likely multiply determined [8] and contingent on both parent and family factors, as well as more direct individual or child factors. Past research suggests that environmental and economic crises impact family functioning and ultimately influence children's mental health $[9,10]$. Moreover, child mental health is often dependent on the functioning and well-being of the family unit $[8,11]$. For example, maternal mental health is often a robust predictor of child mental health and well-being [12, 13]. During COVID-19, a near doubling of maternal anxiety and depression has been observed [14], along with documented disruptions in family relationships and financial strain due to COVID-19 [15-17]. Each of these factors could play a unique role in children's mental health and well-being during COVID-19.

Decades of observational and experimental research has shown that when children feel connected to their caregivers, their developmental health is optimized [18-23]. However, as children move into the later stages of middle childhood, peer relationships take on more primacy. One of the most prominent COVID-19 changes for school-aged children has likely been separation from peers due to school closures and social-distancing orders. The COVID-19 pandemic has also impacted children's daily routines and functioning [24-27]. Indeed, changes in children's sleep routines, levels of screen time, physical activity, and engagement in recreational activities during COVID-19 have been observed [28, 29]. Importantly, research has shown that when children experience changes and disruptions in these individual factors, it can precipitate mental health difficulties [2].

Methodologically rigorous research is needed to highlight targets for intervention for children to recover and thrive in a post-pandemic future. The current multiinformant study of mothers and children aged 9-11 aimed to identify the strongest predictors of child COVID-19 anxiety, depression, and happiness, while leveraging prepandemic data to control for pre-existing mental health and well-being. It is critical to study mental health and wellbeing in middle childhood as this developmental period is marked by a significant increase in mental health disorder symptoms [30], and once increases in mental health are observed, children can be at risk for more sustained mental health struggles across adolescence and adulthood $[31,32]$. We hypothesized that child pre-pandemic mental health, along with maternal mental health and child connectedness to caregivers during COVID-19, would be the strongest predictors of child mental health and well-being during COVID-19. Given the considerable disruptions and shifts in children's daily routines during COVID-19, we also hypothesized that higher screen time and lower sleep, physical activity and connectedness to peers would predict poorer mental health during the COVID-19 pandemic, over and above other predictors. Overall, this study will identify prominent threats to children's mental health during the COVID-19 pandemic and help to inform prevention and intervention efforts.

\section{Materials and methods}

\section{Study design and population}

Mothers and children $(n=846)$ were drawn from the All Our Families (AOF) cohort in Calgary, Canada (Table 1) $[33,34]$. Women were recruited in pregnancy (August 2008-December 2010) and followed for 9-11 years postpartum, including a COVID-19 survey, with over a 70\% retention rate on average. Inclusion criteria were: $(1) \geq 18$ years, (2) fluent in English, (3) gestational age $<24$ weeks, and (4) receiving community-based prenatal care. When children were 8 years old (2017-2019), mothers completed a standardized questionnaire on their child's mental health. During COVID-19 (May-July 2020; $n=1285$ ), mothers completed a COVID-19 survey and were also contacted to invite their children (9-11 years; $M=9.85, \mathrm{SD}=0.78)$ to participate in a COVID-19 child survey (July-August 2020). Of these 1285 mothers, 1021 (79.5\%) provided consent for their child to participate, and of those, 895 (87.7\%) children provided assent to participate. Among children who provided assent, $12(1.3 \%)$ were excluded due to incomplete data and $37(4.2 \%)$ were excluded due to invalid data as they indicated their answers were 'not at all true' (Fig. 1). In Alberta, the first case of COVID-19 was identified on March 5th, 2020 and a state of emergency mandating the closure of all schools and childcare facilities, and the implementation of physical distancing and self-isolation orders, were made on March 15th, 2020. Public schools did not re-open until September 2020. Prior to COVID-19, 97\% of the sample regularly attended school outside of the home. At the time of the COVID-19 survey, $10 \%$ of families reported having a personal experience with COVID-19 (i.e., personal infection, infection of a child, extended family member or close friend), $58 \%$ of all families had some form of financial impact (e.g., at least one parent experienced job loss, loss of main income source, or reduction in employment hours), and over $30 \%$ of mothers reported elevated stress, anxiety and depression, as well as concern about their child's behavior 
Table 1 Descriptive characteristics for the final COVID-19 sample $(n=846)$

\begin{tabular}{|c|c|}
\hline Characteristic & Value \\
\hline \multicolumn{2}{|l|}{ Child sex, no. (\%) } \\
\hline Male & $447(52.8)$ \\
\hline Female & $398(47.1)$ \\
\hline Missing & $1(0.1)$ \\
\hline \multicolumn{2}{|l|}{ Child age, no. (\%) } \\
\hline 9 years & $334(39.5)$ \\
\hline 10 years & $308(36.4)$ \\
\hline 11 years & $203(24.0)$ \\
\hline Missing & $1(0.1)$ \\
\hline \multicolumn{2}{|l|}{ Maternal race/ethnicity, no. (\%) } \\
\hline Asian & $104(12.2)$ \\
\hline Black & $4(0.5)$ \\
\hline First Nations, Inuit, Metis & $2(0.2)$ \\
\hline Latin & $11(1.3)$ \\
\hline Other/mixed & $22(2.6)$ \\
\hline White & $701(82.9)$ \\
\hline Missing & $2(0.3)$ \\
\hline \multicolumn{2}{|l|}{ Household income before COVID-19 ${ }^{\mathrm{a}}$, no. (\%) } \\
\hline$\geq \$ 80,000$ & $679(80.3)$ \\
\hline$\leq \$ 79,999$ & $139(16.4)$ \\
\hline Missing & $28(3.3)$ \\
\hline \multicolumn{2}{|l|}{ Impact of COVID-19 on resources ${ }^{\mathrm{b}}$, no. (\%) } \\
\hline No & $484(57.2)$ \\
\hline Yes & $362(42.8)$ \\
\hline Maternal depression ${ }^{\mathrm{c}}$, mean (SD) & $7.78(5.6)$ \\
\hline Maternal anxiety ${ }^{\mathrm{d}}$, mean (SD) & $11.63(4.04)$ \\
\hline Connection to caregivers ${ }^{\mathrm{e}}$, mean (SD) & $10.70(1.54)$ \\
\hline \multicolumn{2}{|l|}{ Relationship with school peers, no. (\%) } \\
\hline Better & $58(6.9)$ \\
\hline The same & $127(15.0)$ \\
\hline Worse & $646(76.4)$ \\
\hline Missing & $15(1.7)$ \\
\hline Sleep duration, h/night, mean (SD) & $9.23(0.89)$ \\
\hline Physical activity, days/week, mean (SD) & $5.25(1.95)$ \\
\hline Screen time duration, $\mathrm{h} /$ week, mean (SD) & $23.65(11.95)$ \\
\hline Recreational activities, mean (SD) & $30.13(7.97)$ \\
\hline \multicolumn{2}{|l|}{ Mental health at 8-year survey ${ }^{\mathrm{f}}$, mean $(\mathrm{SD})$} \\
\hline Anxiety symptoms & $49.48(10.43)$ \\
\hline Depressive symptoms & $50.08(9.78)$ \\
\hline Adaptive skills & $51.05(9.10)$ \\
\hline \multicolumn{2}{|l|}{ Mental health at COVID-19 survey, mean (SD) } \\
\hline Anxiety symptoms ${ }^{\mathrm{g}}$ & $48.84(10.22)$ \\
\hline Depressive symptoms ${ }^{\mathrm{g}}$ & $48.61(8.07)$ \\
\hline Happiness score ${ }^{\mathrm{e}}$ & $20.73(4.19)$ \\
\hline
\end{tabular}

${ }^{a}$ Measured in Canadian Dollars; ${ }^{b}$ Defined as difficulty meeting financial and/or essential needs; ${ }^{\text {c}}$ Center for Epidemiological Studies of Depression Short Form (CES-D-10); ${ }^{\mathrm{d}}$ Spielberger State Anxiety Inventory-Short Form (SSAI-SF); ${ }^{e}$ Middle Years Development Instrument (MDI); ${ }^{\mathrm{f}}$ Behavior Assessment System for Children, second edition (BASC-2); ${ }^{\mathrm{g}}$ Behavior Assessment System for Children (BASC-3)

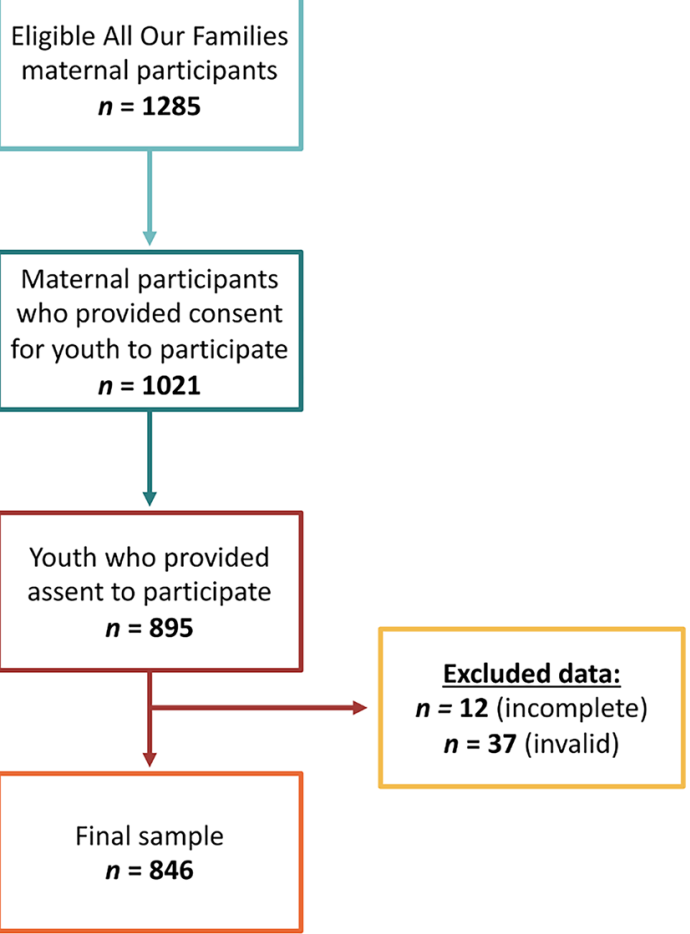

Fig. 1 .

and mood $[35,36]$. All procedures were approved by the institutional ethics board.

\section{Pre-pandemic factors}

Prior levels of child mental health are important confounders to consider when examining the relation between COVID-19 predictors and child mental health outcomes. To control for these confounders, we included maternal report of children's pre-pandemic anxiety, depressive symptoms or adaptive skills (e.g., adaptability, communication, and social skills) at 8 years of age (2017-2019), using the Behavior Assessment System for Children (BASC-2) [37]. Standardized T-scores were used with higher scores indicating greater symptoms or adaptive behavior at age 8 . We also controlled for child sex (male, female) and age (9-11 years), since these factors are significantly associated with a number of the predictors [38-41] as well as the child mental health outcomes [42-47].

\section{COVID-19 predictors of child mental health and well-being}

Maternal-Report of Family COVID-19 Factors (May-July 2020) Using the 10-item Center for Epidemiological Studies of Depression Short Form (CES-D-10) mothers self-reported symptoms of depression in the past week. The CES-D-10 has strong psychometric properties and is frequently used 
in primary care settings to screen for depressive symptoms $[48,49]$. Internal consistency in the current sample was high $(\alpha=0.87)$. Using the 6-item Spielberger State Anxiety Inventory Short Form (SSAI-SF), mothers self-reported on current symptoms of anxiety [50]. The SSAI-SF has good internal consistency and has been validated for use with mothers $[51,52]$. Internal consistency was high $(\alpha=0.86)$. Mothers also reported whether COVID-19 had impacted their ability to meet family needs $[1$, minor, moderate or major difficulty meeting financial and/or essential needs (i.e., rent or mortgage payments, utilities and groceries); 0 , no impact or too soon to tell].

Child-Report of Individual COVID-19 Factors (July-August 2020) During COVID-19, children reported on the parent-child relationship using the Connections with Adults at Home subscale of the Middle Years Development Instrument (MDI) [53]. Children indicated on three items (e.g., "In my home there is a parent or another adult who listens to me when I have something to say.") how much they agree with each statement (1, not at all true; 4 , very much true) and higher scores indicated greater connection to caregivers. The Connections with Adults at Home subscale of the MDI showed adequate reliability in the current sample $(\alpha=0.70)$.

During COVID-19, children also reported on the duration of time they spent using electronic devices on a typical weekday and weekend day outside of schoolwork $(0$, none; 7,7 or more hours), and a weighted weekly average was derived with higher scores indicating greater screen time duration per week. Children self-reported how many of the last 7 days they participated in physical activity that made their heart rate go up for at least 60 minutes (0, 0 days; 7 , 7 days), and how long they slept on a typical night (1, less than 7 hours; 8,10 hours or more). Higher scores indicated longer durations of physical activity and sleep. Children reported how often they engaged in 11 different recreational activities (e.g., crafts, hobbies, music, and exploring nature; 0 , never; 5 many times a day) and a summed score was calculated across all items. Higher scores represent greater engagement in recreational activities. Lastly, children reported how connected they currently (i.e., during COVID19) felt to their school peers (1, less; 3 , more).

\section{Outcome measures: child mental health and well-being during COVID-19}

As children emerge into the late stages of middle childhood, they are considered the best informants of their own behavior [54]. Thus, children self-reported on symptoms of depression and anxiety during COVID-19 (July-August 2020), using the Behavior Assessment System for Children (BASC-3) [55]. Standardized T-scores were used, with higher scores indicating greater symptoms. The BASC-3 is a widely used tool to assess mental health difficulties and has strong psychometric properties [55]. Internal consistency was high $(\alpha=0.83$ and $\alpha=0.88$, respectively).

Using the Middle Years Development Instrument (MDI) [53], children also self-reported their levels of happiness, or subjective well-being. Children indicated on five items how much they agree with each statement (1, disagree a lot; 5 , agree a lot) and higher scores indicated greater levels of happiness. The MDI has strong psychometric properties [53] and showed high reliability in the current sample $(\alpha=0.86)$.

\section{Statistical analysis}

Multivariable linear regression analysis was used to predict each outcome independently - anxiety, depression, and happiness. Effect modification was tested in each of the regression models based on child sex (male, female), child age $(9,10$, 11 ), and previous at-risk mental health status (T-score $\geq 60$ vs. T-score $<60$ ) at 8 years of age (BASC-2), using Chi-square difference tests with the Satorra-Bentler scaling correction to adjust for nested models [56]. As noted above, the BASC-2 subscales for anxiety and depression were used as covariates for COVID-19 mental health. However, for the happiness model, child happiness was not measured pre-COVID-19, thus the BASC-2 adaptive skills composite (e.g., social skills, adaptability, leadership, and communication skills) at age 8 was used as a pre-pandemic proxy, as components of this composite have been shown to correlate with happiness [57]. All analyses were conducted in Mplus 8.1 [58], using Robust Maximum Likelihood [59]. Standardized estimates $(B)$ with 95\% confidence intervals (CIs) are reported.

\section{Missing data}

When compared to all families who completed the maternal COVID-19 survey $(n=1285)$, mothers of children who completed the COVID-19 child survey $(n=846)$ had lower depressive symptoms $(t=-2.34, p=0.020)$ and were more likely to report having a partner during COVID-19 $(t=-2.86, p=0.004)$. The two groups did not differ on measures of maternal anxiety or impact of COVID-19 on family resources, and children who participated did not differ based on child age, sex, or mental health pre-COVID-19 (anxiety, depression).

\section{Results}

\section{Descriptive statistics}

Descriptive statistics and correlations are presented in Tables 1 and 2, respectively. During COVID-19, 13.8\% $(n=122)$ of children reported anxiety symptoms, and $8.2 \%$ 
$(n=72)$ reported depressive symptoms, that were in the at-risk or clinical score range $(t$-score $\geq 60)$. Based on the standardized scoring for the MDI, $44.2 \%(n=374)$ of the children reported high levels of happiness. As displayed in Table 2, anxiety and depression subscales of the BASC-2 at 8 years (maternal report) and the BASC-3 at COVID19 (child self-report; $r=0.31, p<0.001$, respectively) were moderately correlated. Adaptive skills at age 8 (maternal report) and happiness at COVID-19 (child self-report) were also significantly correlated $(r=0.24, p<0.001)$.

\section{Model testing}

Child anxiety symptoms. After controlling for child sex, age, and anxiety symptoms pre-COVID-19, connectedness to caregivers $(B-0.16$; 95\% CI, -0.22 to -0.09$)$, child sleep $(B-0.11 ; 95 \%$ CI -0.19 to -0.04$)$, and child screen time duration ( $B 0.11$; 95\% CI 0.04-0.17) were significant unique predictors of child COVID-19 anxiety symptoms (Table 3 ). Overall, the predictors accounted for $17 \%$ of the variance in the model.

Child depressive symptoms After controlling for child sex, age, and depressive symptoms pre-COVID-19, connectedness to caregivers $(B-0.26 ; 95 \% \mathrm{CI}-0.32$ to -0.21$)$ and child screen time duration $(B 0.09 ; 95 \%$ CI $0.02-0.16)$ were significant unique predictors of child COVID-19 depressive symptoms (Table 3). Overall, the predictors accounted for $19 \%$ of the variance in the model.

Child happiness After controlling for child sex, age, and adaptive skills pre-COVID-19, connectedness to caregivers ( $B$ 0.36; 95\% CI $0.28-0.39)$ was a significant unique predictor of child happiness during COVID-19 (Table 3). Overall, the predictors accounted for $22 \%$ of the variance in the model.

When examining the anxiety, depression, and happiness regression models stratified by sex (male, female), age $(9,10,11)$, and previous mental health status (BASC-2 T-score $\geq 60$ at 8 years of age vs. T-score $<60$ ), independently, no significant differences were found for the overall models (Table 4).

\section{Discussion}

Child and family stressors related to COVID-19 have been pervasive and the world has become an even more challenging place for children to thrive. Thriving is all the more difficult as children transition to early adolescence, a period marked by significant biological and contextual change [60], coinciding with an increase in mental health difficulties [30]. Thus, there is urgency in identifying threats to children's mental health, to build health capital and to inform universal and targeted prevention and intervention strategies based on the needs of children on account of the unprecedented disruptions brought on by COVID-19. To answer these questions, and inform these efforts, cohort studies that can account for prior mental health status are needed. Using multi-informant data from a longitudinal cohort, this study identifies the most salient child and family factors predicting child mental health during COVID-19.

One of the most prominent predictors of child mental health difficulties is prior mental health [61, 62]. The large effects sizes [63] found herein between pre-pandemic and COVID-19 child mental health suggests that children who struggled with mental health symptoms prior to COVID-19, are also struggling during COVID-19. This reiterates the need for high-quality and accessible mental health resources for children, and in the context of COVID-19, increased points of access potentially through e-mental health, virtual appointments, and evidence informed online interventions. Follow-up research is needed to understand the patterns of mental health that change or are maintained as the COVID-19 pandemic unfolds. Identifying the mechanism that explain why some children will experience long-term mental health difficulties after the pandemic, whereas some children will not, is an urgent research priority.

After accounting for children's pre-existing mental health and well-being, several salient and unique COVID-19-specific predictors emerged. Child-reported sense of connectedness to caregivers was a moderate to strong predictor of their COVID-19 depression, anxiety, and happiness. This finding is consistent with a robust body of literature that supports the importance of parental warmth and connection for children's developmental health outcomes [18-21, 64]. Moreover, connection to caregivers may be playing a particularly salient role when access to other traditional supports (e.g., peers, teachers and coaches) is limited or unavailable due to COVID-19 restrictions. When considering prevention and intervention strategies to recover from COVID-19, bolstering connectedness within the family unit may have downstream impact on children's mental health [8].

Over and above the effects of pre-COVID-19 mental health and family connections, child-reported screen time and sleep duration predicted COVID-19 child mental health. These small effects suggest that children who engaged in higher durations of screen time during COVID-19 also reported higher levels of depressive and anxiety symptoms. Children who reported lower durations of sleep reported higher levels of anxiety symptoms. These findings are consistent with past research showing that healthy daily habits for school-aged children can reduce the risk for mental health difficulties and increase well-being [32, 65-68]. Clinically, especially in times of great disruption, it is important to encourage families to establish and maintain healthy structured routines including establishing adequate sleep schedules and hygiene, and to involve children in creating 


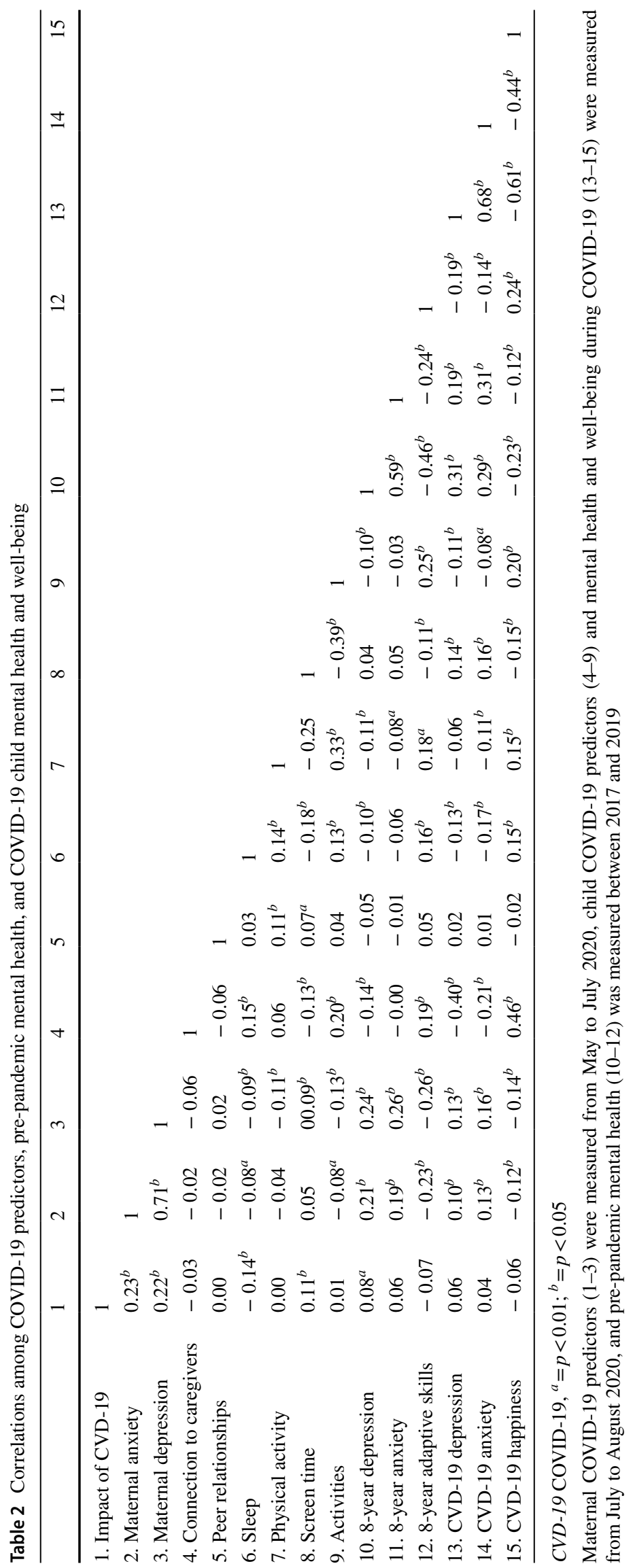


Table 3 Multivariable linear regressions predicting child self-report mental health and well-being during COVID-19

\begin{tabular}{|c|c|c|c|}
\hline \multirow[t]{2}{*}{ Predictors } & \multicolumn{3}{|l|}{ Model } \\
\hline & $\begin{array}{l}\text { Anxiety } t \text {-score } \\
\text { Estimate }(B), 95 \%(\mathrm{CI})\end{array}$ & $\begin{array}{l}\text { Depression } t \text {-score } \\
\text { Estimate }(B), 95 \%(\mathrm{CI})\end{array}$ & $\begin{array}{l}\text { Happiness score } \\
\text { Estimate }(B), 95 \%(\mathrm{CI})\end{array}$ \\
\hline \multicolumn{4}{|l|}{ Pre-pandemic factors } \\
\hline Female & $0.07,0.01$ to $0.13 *$ & $0.01,-0.05$ to 0.07 & $-0.05,-0.11$ to 0.01 \\
\hline Age & $-0.02,-0.08$ to 0.04 & $0.03,-0.03$ to 0.09 & $-0.13,-0.19$ to $-0.07 *$ \\
\hline Age 8 anxiety symptoms & $0.28,0.22$ to $0.35 *$ & - & - \\
\hline Age 8 depressive symptoms & - & $0.26,0.19$ to $0.32 *$ & - \\
\hline Age 8 adaptive skills & - & - & $0.14,0.07$ to $0.21 *$ \\
\hline \multicolumn{4}{|c|}{ Family COVID-19 factors (May-July 2020) } \\
\hline Impact on resources & $-0.02,-0.09$ to 0.04 & $0.00,-0.01$ to 0.06 & $-0.02,-0.08$ to 0.04 \\
\hline Maternal depressive symptoms & $0.04,-0.05$ to 0.12 & $0.05,-0.03$ to 0.13 & $-0.04,-0.12$ to 0.04 \\
\hline Maternal anxiety symptoms & $0.04,-0.05$ to 0.12 & $-0.01,-0.09$ to 0.08 & $-0.04,-0.12$ to 0.05 \\
\hline \multicolumn{4}{|c|}{ Child COVID-19 factors (July-August 2020) } \\
\hline Connectedness to caregivers & $-0.16,-0.22$ to $-0.09^{*}$ & $-0.26,-0.32$ to $-0.21^{*}$ & $0.36,0.28$ to $0.39 *$ \\
\hline Connection with school peers & $0.01,-0.06$ to 0.08 & $0.02,-0.05$ to 0.09 & $-0.03,-0.10$ to 0.04 \\
\hline Sleep & $-0.11,-0.19$ to $-0.04 *$ & $-0.05,-0.13$ to 0.03 & $0.04,-0.03$ to 0.11 \\
\hline Physical activity & $-0.04,-0.10$ to 0.03 & $0.02,-0.04$ to 0.09 & $0.06,-0.01$ to 0.12 \\
\hline Screen time & $0.11,0.04$ to $0.17 *$ & $0.09,0.02$ to $0.16^{*}$ & $-0.04,-0.11$ to 0.03 \\
\hline Recreational activities & $0.02,-0.05$ to 0.09 & $0.01,-0.07$ to 0.08 & $0.05,-0.02$ to 0.12 \\
\hline $\mathrm{R}^{2}$ & $0.17,0.13$ to $0.22 *$ & $0.19,0.14$ to $0.24 *$ & $0.22,0.18$ to $0.27 *$ \\
\hline
\end{tabular}

*Estimates in which $95 \%$ CIs do not include 0

Table 4 Model stratification analyses

\begin{tabular}{ll}
\hline Stratified by & Difference test $^{\mathrm{a}}$ \\
\hline Anxiety model & \\
Sex & $\chi^{2}(11)=9.93, p=0.536$ \\
Age & $\chi^{2}(22)=24.23, p=0.335$ \\
Age 8 anxiety & $\chi^{2}(11)=8.61, p=0.658$ \\
Depression model & \\
Sex & $\chi^{2}(11)=6.45, p=0.842$ \\
Age & $\chi^{2}(22)=25.79, p=0.261$ \\
Age 8 depression & $\chi^{2}(11)=12.19, p=0.349$ \\
Happiness model & \\
Sex & $\chi^{2}(11)=8.99, p=0.623$ \\
Age & $\chi^{2}(22)=25.60, p=0.269$ \\
Age 8 adaptive skills & $\chi^{2}(11)=7.23, p=0.780$ \\
\hline
\end{tabular}

${ }^{a}$ Chi-square difference test using the Satorra-Bentler scaling correction

family media plans $[69,70]$ that foster healthy recreational device habit use (e.g., limits on duration).

Although pre-pandemic associations between maternal mental health and child mental health are well established $[12,13]$, we did not find that maternal anxiety or depression predicted child mental health and well-being during COVID-19. In addition, somewhat surprisingly given the critical role of peers in middle childhood development, connectedness to peers did not emerge as a significant predictor of mental health and well-being during COVID-19. Due to strict social-distancing orders, peer interactions were reduced and less proximal during this survey period. Thus, it appears that the more salient predictors of child mental health and well-being during COVID-19 were those more proximal, accessible, or directly experienced by the child (e.g., connectedness to caregivers, screen time, and sleep) versus ones that were more external to them (e.g., family income, maternal mental health, and peer interactions).

When the regression models were stratified by child age, sex, or past psychopathology (i.e., scores above the clinical cutoffs), no significant differences were found. For this sample, the child and family COVID-19 predictors observed in this study seem to be impacting youth mental health across age, sex, and prior mental illness, comparably.

\section{Limitations}

Using a large longitudinal cohort with both maternal and child self-report, this study has a number of strengths. However, the following limitations are noted. First, the women recruited into the All Our Families cohort are generally representative of those living in an urban setting with access to universal health care, and consequently, risk estimates for populations more vulnerable to poor outcomes may be underestimated. Second, only a portion of the cohort 
participated in the COVID-19 survey likely resulting is some selection bias. However, a recent study using the All Our Families cohort and applying longitudinal non-response weights showed that complete case analysis and a weighted analyses produced similar results [14]. Thus, the direction and pattern of the current results are hypothesized to be similar for the broader sample. Third, although controlling for prior mental health improves the design of this study, and maternal and child reports were collected at different time points during COVID-19, several child-reported predictors and outcomes were measured cross-sectionally. Further research is needed to better assess how COVID-19 predictors and mental health outcomes are related over the course of the COVID-19 pandemic, and how this impacts children's long-term outcomes. Lastly, the COVID-19 pandemic is not a homogeneous event and youth have been differentially impacted based on a variety of COVID-19 factors (e.g., school closure, parent availability, public health measures, and exposure to COVID-19)[71, 72]. Although this study was designed to better understand some of the influential factors associated with child mental health during the COVID-19 pandemic, it does not encapsulate all factors present during the pandemic (e.g., different public health mandates by country, different schooling modalities, and varying levels of exposure to COVID-19).

\section{Conclusions}

In addition to previous mental health difficulties, connections with caregivers and healthy device and sleep habits are important predictors of child mental health during COVID19. Fostering parent-child connections and promoting healthy device and sleep habits are critical modifiable factors that warrant attention in pandemic and post-pandemic mental health recovery planning. These findings are relevant for pediatric practice and the promotion of routines (e.g., sleep, physical activity, and screen time), resources (e.g., access to mental health education and treatment), and relationships (e.g., parent-child) for youth and their families to enhance children's emotional health and well-being. These strategies would likely be beneficial for many children, but further research is needed to determine if vulnerable groups not specifically targeted in this study require other forms of supportive or preventative measures. The strategies used to care for children and their families during this time of global crisis could mitigate the potential cost of COVID-19 on children's lifelong trajectories [73]. Additional longitudinal research is needed to determine if the predictors found herein remain relevant throughout COVID-19, and in a postpandemic future.
Acknowledgements The authors acknowledge the contributions of the All Our Families research team and thank the participants who took part in the study.

Author contributions BM and SM secured funding for data collection, conceptualized and designed the study, conducted data analyses, drafted the manuscript, and reviewed and revised the manuscript. NR secured funding for data collection and critically reviewed the manuscript for important intellectual content. SM and ST conceptualized the cohort study, designed the data collection instruments and study methodology, secured funding for data collection, and critically reviewed the manuscript for important intellectual content. All the authors approved the final manuscript as submitted and agree to be accountable for all aspects of the work.

Funding The child AOF COVID-19 Impact survey was supported by an Interdisciplinary Research Grant awarded to Drs. Madigan, McArthur, Racine, McDonald, and Tough from the Children and Screens Institute of Digital Media and Child Development. The All Our Families study was supported by Alberta Innovates Health Solutions Interdisciplinary Team grant 200700595, the Alberta Children's Hospital Foundation, the Max Bell Foundation, and the Canadian Institutes of Health Research, Rapid COVID-19 response grant. The principal coinvestigators of the All Our Families Study are Drs. Tough and McDonald. Research support was provided to Dr. Madigan by the Canada Research Chairs program. Dr. McArthur was supported by the Alberta Children's Hospital Research Institute. Dr. Racine was supported by the Alberta Innovates Clinician Fellowship.

Availability of data and materials The All Our Families meta-data are available through a third-party data curator, SAGE/Policywise (https:// sagemetadata.policywise.com/nada/index.php/catalog/1). Investigators can submit a proposal that has been approved by an independent ethics and scientific review committee to obtain de-identified individual participant data. Data requestors will need to sign confidentiality and access agreements.

Code availability Not applicable.

\section{Declarations}

Conflict of interest The authors have no conflicts of interest to disclose.

Ethics approval The current study was approved by the University of Calgary Institutional Review Board. The procedures used in this study adhere to the tenets of the Declaration of Helsinki.

Consent to participate Informed consent was obtained from all mothers included in the study. In addition, all children provided assent to participate.

Consent for publication Not applicable.

\section{References}

1. Christakis DA (2020) Pediatrics and COVID-19. JAMA 324(12):1147. https://doi.org/10.1001/jama.2020.14297

2. Gruber J, Prinstein M, Abramowitz JS, Albano AM, Aldao A, Borelli J et al (2020) Mental health and clinical psychological 
science in the time of COVID-19: challenges, opportunities, and a call to action. Am Psychol. https://doi.org/10.1037/amp0000707

3. Hafstad GS, Sætren SS, Wentzel-Larsen T, Augusti E-M (2021) Adolescents' symptoms of anxiety and depression before and during the Covid-19 outbreak - a prospective population-based study of teenagers in Norway. The Lancet Regional Health Europe. https://doi.org/10.1016/j.lanepe.2021.100093

4. Bignardi G, Dalmaijer ES, Anwyl-Irvine AL, Smith TA, Siugzdaite R, Uh S et al (2020) Longitudinal increases in childhood depression symptoms during the COVID-19 lockdown. Arch Dis Child. https://doi.org/10.1136/archdischild-2020-320372

5. Magson NR, Freeman JYA, Rapee RM, Richardson CE, Oar EL, Fardouly J (2021) Risk and protective factors for prospective changes in adolescent mental health during the COVID-19 pandemic. J Youth Adolesc 50(1):44-57. https://doi.org/10.1007/ s10964-020-01332-9

6. Racine N, Cooke JE, Eirich R, Korczak DJ, McArthur B, Madigan S (2020) Child and adolescent mental illness during COVID-19: a rapid review. Psychiatry Res 292:113307. https://doi.org/10. 1016/j.psychres.2020.113307

7. Wade M, Prime H, Browne DT (2020) Why we need longitudinal mental health research with children and youth during (and after) the COVID-19 pandemic. Psychiatry Res 290:113143. https://doi. org/10.1016/j.psychres.2020.113143

8. Prime H, Wade M, Browne DT (2020) Risk and resilience in family well-being during the COVID-19 pandemic. Am Psychol 75(5):631-643. https://doi.org/10.1037/amp0000660

9. Fonseca G, Cunha D, Crespo C, Relvas AP (2016) Families in the context of macroeconomic crises: a systematic review. J Fam Psychol 30(6):687-697. https://doi.org/10.1037/fam0000230

10. Masten AS, Narayan AJ (2012) Child Development in the context of disaster, war, and terrorism: pathways of risk and resilience. Annu Rev Psychol 63(1):227-257. https://doi.org/10.1146/annur ev-psych-120710-100356

11. Bronfenbrenner U, Ceci SJ (1994) Nature-nuture reconceptualized in developmental perspective: a bioecological model. Psychol Rev 101(4):568-586. https://doi.org/10.1037/0033-295x.101.4.568

12. Rogers A, Obst S, Teague SJ, Rossen L, Spry EA, Macdonald JA et al (2020) Association between maternal perinatal depression and anxiety and child and adolescent development: a metaanalysis. JAMA Pediatr 174(11):1082-1092. https://doi.org/10. 1001/jamapediatrics.2020.2910

13. Madigan S, Oatley H, Racine N, Fearon RMP, Schumacher L, Akbari E et al (2018) A meta-analysis of maternal prenatal depression and anxiety on child socioemotional development. J Am Acad Child Adolesc Psychiatry 57(9):645-57.e8. https://doi. org/10.1016/j.jaac.2018.06.012

14. Racine N, Hetherington E, McArthur BA, McDonald S, Edwards SA, Tough $S$ et al (2021) Maternal depressive and anxiety symptoms before and during the COVID-19 pandemic in Canada: a longitudinal analysis. Lancet Psychiatry. https://doi.org/10.1016/ s2215-0366(21)00074-2

15. Cameron EE, Joyce KM, Delaquis CP, Reynolds K, Protudjer JLP, Roos LE (2020) Maternal psychological distress \& mental health service use during the COVID-19 pandemic. J Affect Disord 276:765-774. https://doi.org/10.1016/j.jad.2020.07.081

16. Gassman-Pines A, Ananat EO, Fitz-Henley J (2020) COVID19 and parent-child psychological well-being. Pediatrics 146(4):e2020007294. https://doi.org/10.1542/peds.2020-007294

17. Patrick SW, Henkhaus LE, Zickafoose JS, Lovell K, Halvorson A, Loch S et al (2020) Well-being of parents and children during the COVID-19 pandemic: a national survey. Pediatrics 146(4):e2020016824. https://doi.org/10.1542/peds.2020-016824

18. Rodrigues M, Sokolovic N, Madigan S, Luo Y, Silva V, Misra $S$ et al (2021) Paternal sensitivity and children's cognitive and socioemotional outcomes: a meta-analytic review. Child Dev. https://doi.org/10.1111/cdev.13545

19. Madigan S, Brumariu LE, Villani V, Atkinson L, Lyons-Ruth K (2016) Representational and questionnaire measures of attachment: a meta-analysis of relations to child internalizing and externalizing problems. Psychol Bull 142(4):367-399. https://doi.org/ 10.1037/bul0000029

20. Madigan S, Prime H, Graham SA, Rodrigues M, Anderson N, Khoury J et al (2019) Parenting behavior and child language: a meta-analysis. Pediatrics 144(4):20183556. https://doi.org/10. 1542/peds.2018-3556

21. Chen P, Harris KM (2019) Association of positive family relationships with mental health trajectories from adolescence to midlife. JAMA Pediatr 173(12):e193336. https://doi.org/10.1001/jamap ediatrics.2019.3336

22. Paul IM, Savage JS, Anzman-Frasca S, Marini ME, Beiler JS, Hess LB et al (2018) Effect of a responsive parenting educational intervention on childhood weight outcomes at 3 years of age: the INSIGHT randomized clinical trial. JAMA 320(5):461-468. https://doi.org/10.1001/jama.2018.9432

23. Roberts MY, Curtis PR, Sone BJ, Hampton LH (2019) Association of parent training with child language development: a systematic review and meta-analysis. JAMA Pediatr 173(7):671-680. https://doi.org/10.1001/jamapediatrics.2019.1197

24. Carroll N, Sadowski A, Laila A, Hruska V, Nixon M, Ma DWL et al (2020) The impact of COVID-19 on health behavior, stress, financial and food security among middle to high income Canadian families with young children. Nutrients 12(8):2352. https:// doi.org/10.3390/nu12082352

25. Drouin M, McDaniel BT, Pater J, Toscos T (2020) How parents and their children used social media and technology at the beginning of the COVID-19 pandemic and associations with anxiety. Cyberpsychol Behav Soc Netw 23(11):727-736. https://doi.org/ 10.1089/cyber.2020.0284

26. Dutta K, Mukherjee R, Sen D, Sahu S (2020) Effect of COVID-19 lockdown on sleep behavior and screen exposure time: an observational study among Indian school children. Biol Rhythm Res. https://doi.org/10.1080/09291016.2020.1825284

27. Moore SA, Faulkner G, Rhodes RE, Brussoni M, Chulak-Bozzer $\mathrm{T}$, Ferguson LJ et al (2020) Impact of the COVID-19 virus outbreak on movement and play behaviours of Canadian children and youth: a national survey. Int J Behav Nutr Phys Activity. https:// doi.org/10.1186/s12966-020-00987-8

28. López-Gil JF, Tremblay MS, Brazo-Sayavera J (2021) Changes in healthy behaviors and meeting 24-h movement guidelines in Spanish and Brazilian preschoolers, children and adolescents during the COVID-19 lockdown. Children. https://doi.org/10.3390/child ren8020083

29. Moore SA, Faulkner G, Rhodes RE, Brussoni M, Chulak-Bozzer T, Ferguson LJ et al (2020) Impact of the COVID-19 virus outbreak on movement and play behaviours of Canadian children and youth: a national survey. Int J Behav Nutr Phys Act 17(1):85. https://doi.org/10.1186/s12966-020-00987-8

30. Whiteford HA, Degenhardt L, Rehm J, Baxter AJ, Ferrari AJ, Erskine HE et al (2013) Global burden of disease attributable to mental and substance use disorders: findings from the Global Burden of Disease Study 2010. The Lancet 382(9904):1575-1586. https://doi.org/10.1016/s0140-6736(13)61611-6

31. Prinstein MJ, Giletta M (2016) Peer relations and developmental psychopathology. In Chicchetti (ed) Developmental psychopathology: theory and method, John Wiley \& Sons Inc., Hoboken, p. 527-579

32. Schonert-Reichl KA (2011) Middle childhood inside and out: the psychological and social worlds of Canadian children ages 9-12. University of British Columbia, Full Report 
33. Tough SC, McDonald SW, Collisson BA, Graham SA, Kehler H, Kingston D et al (2017) Cohort profile: the all our babies pregnancy cohort (AOB). Int J Epidemiol 46(5):1389-1390. https:// doi.org/10.1093/ije/dyw363

34. McDonald SW, Lyon AW, Benzies KM, McNeil DA, Lye SJ, Dolan SM et al (2013) the all our babies pregnancy cohort: design, methods, and participant characteristics. Bmc Pregnancy Childb. https://doi.org/10.1186/1471-2393-13-S1-S2

35. McDonald S, Edwards S, Hetherington E, Racine N, Mueller M, McArthur BA et al (2020) Experiences of Albertan families with young children during the COVID-19 pandemic: descriptive report. University of Calgary, Calgary

36. McDonald S, Madigan S, McArthur BA, Racine N, Wu M, Pitt T et al (2021) Experiences of Albertan children during the COVID19 pandemic: a technical report from the all our families cohort. University of Calgray, Calgary

37. Kamphaus RW (2015) Behavior assessment system for children, Second Edition (BASC-2). In: Cautin RL, Lilienfeld SO (eds) The encyclopedia of clinical psychology, John Wiley and Sons, Chichester, West Sussex; Madden, MA

38. Sallis JF (2000) Age-related decline in physical activity: a synthesis of human and animal studies. Med Sci Sports Exerc 32(9):1598-1600. https://doi.org/10.1097/00005768-20000 9000-00012

39. Keyes KM, Maslowsky J, Hamilton A, Schulenberg J (2015) The great sleep recession: changes in sleep duration among US adolescents, 1991-2012. Pediatrics 135(3):460-468. https://doi.org/ 10.1542/peds.2014-2707

40. Rideout V (2015) The common sense consensus: media use by tweens and teens. Common Sense Media, San Francisco

41. Statistics Canada (2020) Table 13-10-0392-01 Deaths and agespecific mortality rates, by selected grouped causes. https://doi. org/10.25318/1310039201-eng. Accessed 14 Oct 2020

42. Kaye-Tzadok A, Kim SS, Main G (2017) Children's subjective well-being in relation to gender-what can we learn from dissatisfied children? Child Youth Serv Rev 80:96-104. https://doi. org/10.1016/j.childyouth.2017.06.058

43. Orben A, Lucas RE, Fuhrmann D, Kievit RA (2020) Trajectories of adolescent life satisfaction. PsyArXiv, Web. https://doi.org/10. 31234/osf.io/y8c. Accessed 20 Aug 2020

44. McArthur BA, Burke TA, Connolly SL, Olino TM, Lumley MN, Abramson LY et al (2019) A longitudinal investigation of cognitive self-schemas across adolescent development. J Youth Adolesc 48(3):635-647. https://doi.org/10.1007/s10964-018-00981-1

45. Campbell OLK, Bann D, Patalay P (2021) The gender gap in adolescent mental health: a cross-national investigation of 566,829 adolescents across 73 countries. SSM Population Health. https:// doi.org/10.1016/j.ssmph.2021.100742

46. Olfson M, Blanco C, Wang S, Laje G, Correll CU (2014) National trends in the mental health care of children, adolescents, and adults by office-based physicians. JAMA Psychiat 71(1):81. https://doi.org/10.1001/jamapsychiatry.2013.3074

47. Gardner W, Pajer KA, Kelleher KJ, Scholle SH, Wasserman RC (2002) Child sex differences in primary care clinicians' mental health care of children and adolescents. Arch Pediatr Adolesc Med 156(5):454. https://doi.org/10.1001/archpedi.156.5.454

48. Andresen EM, Malmgren JA, Carter WB, Patrick DL (1994) Screening for depression in well older adults: evaluation of a short form of the CES-D (Center for Epidemiologic Studies Depression Scale). Am J Prev Med 10(2):77-84

49. Bjorgvinsson T, Kertz SJ, Bigda-Peyton JS, McCoy KL, Aderka IM (2013) Psychometric properties of the CES-D-10 in a psychiatric sample. Assessment 20(4):429-436. https://doi.org/10.1177/ 1073191113481998

50. Marteau TM, Bekker H (1992) The development of a six-item short-form of the state scale of the Spielberger State-Trait Anxiety
Inventory (STAI). Br J Clin Psychol 31(3):301-306. https://doi. org/10.1111/j.2044-8260.1992.tb00997.x

51. Tluczek A, Henriques JB, Brown RL (2009) Support for the reliability and validity of a six-item state anxiety scale derived from the State-Trait Anxiety Inventory. J Nurs Meas 17(1):19-28. https://doi.org/10.1891/1061-3749.17.1.19

52. Bayrampour H, McDonald S, Fung T, Tough S (2014) Reliability and validity of three shortened versions of the State Anxiety Inventory scale during the perinatal period. J Psychosom Obstet Gynaecol 35(3):101-107. https://doi.org/10.3109/0167482X. 2014.950218

53. Schonert-Reichl KA, Guhn M, Gadermann AM, Hymel S, Sweiss L, Hertzman C (2013) Development and validation of the middle years development instrument (MDI): assessing children's well-being and assets across multiple contexts. Soc Indic Res 114(2):345-369. https://doi.org/10.1007/s11205-012-0149-y

54. De Los RA, Augenstein TM, Wang M, Thomas SA, Drabick DAG, Burgers DE et al (2015) The validity of the multi-informant approach to assessing child and adolescent mental health. Psychol Bull 141(4):858

55. Reynolds CR, Kamphaus RW (2015) Behavior assessment system for children, 3rd edn. NCS Person, Inc., Bloomington

56. Satorra A, Bentler PM (2010) Ensuring positiveness of the scaled difference Chi-square test statistic. Psychometrika 75(2):243-248. https://doi.org/10.1007/s11336-009-9135-y

57. Hodge K, Danish S, Martin J (2013) Developing a conceptual framework for life skills interventions. Couns Psychol 41(8):1125-1152. https://doi.org/10.1177/0011000012462073

58. Muthén L, Muthén B (2017) Mplus statistical modeling software: Release 8.0. Muthén \& Muthén, Los Angeles

59. Graham JW (2009) Missing data analysis: making it work in the real world. Annu Rev Psychol 60:549-576. https://doi.org/10. 1146/annurev.psych.58.110405.085530

60. Arain M, Haque M, Johal L, Mathur P, Nel W, Rais A et al (2013) Maturation of the adolescent brain. Neuropsychiatr Dis Treat 9:449. https://doi.org/10.2147/NDT.S39776

61. Hankin BL (2015) Depression from childhood through adolescence: risk mechanisms across multiple systems and levels of analysis. Curr Opin Psychol 4:13-20. https://doi.org/10.1016/j. copsyc.2015.01.003

62. Roza SJ, Hofstra MB, Van Der Ende J, Verhulst FC (2003) Stable prediction of mood and anxiety disorders based on behavioral and emotional problems in childhood: a 14-year follow-up during childhood, adolescence, and young adulthood. Am J Psychiatry 160(12):2116-2121. https://doi.org/10.1176/appi.ajp.160.12.2116

63. Funder DC, Ozer DJ (2019) Evaluating effect size in psychological research: sense and nonsense. Adv Methods Pract Psychol Sci 2(2):156-168. https://doi.org/10.1177/2515245919847202

64. Savage JS, Birch LL, Marini M, Anzman-Frasca S, Paul IM (2016) Effect of the insight responsive parenting intervention on rapid infant weight gain and overweight status at age 1 year: a randomized clinical trial. JAMA Pediatr 170(8):742-749. https:// doi.org/10.1001/jamapediatrics.2016.0445

65. Coyne SM, Hurst JL, Dyer WJ, Hunt Q, Schvanaveldt E, Brown $S$ et al (2021) Suicide risk in emerging adulthood: associations with screen time over 10 years. J Youth Adolesc. https://doi.org/ 10.1007/s10964-020-01389-6

66. Khan A, Uddin R, Lee EY (2021) Excessive recreational Internet use was associated with poor mental health in adolescents. Acta Paediatr 110(2):571-573. https://doi.org/10.1111/apa.15528

67. Hoare E, Werneck AO, Stubbs B, Firth J, Collins S, Corder K et al (2020) Association of child and adolescent mental health with adolescent health behaviors in the UK millennium cohort. JAMA Netw Open 3(8):e2011381. https://doi.org/10.1001/jamanetwor kopen.2020.11381 
68. Cairns KE, Yap MBH, Pilkington PD, Jorm AF (2014) Risk and protective factors for depression that adolescents can modify: a systematic review and meta-analysis of longitudinal studies. J Affect Disord 169:61-75. https://doi.org/10.1016/j.jad.2014.08. 006

69. American Academy of Pediatrics. (2019) Family Media Plan. https://www.healthychildren.org/English/media/Pages/default. aspx ?gclid=EAIaIQobChMIoq2F-eiA3QIVUFuGCh3e0gDnE AAYBCAAEgJqNPD_BwE. Accessed 8 July 2019

70. Kroshus E, Christakis D (2021) Family media use planning with teens-is it time for shared decision-making? JAMA Pediatr. https://doi.org/10.1001/jamapediatrics.2020.5637

71. Chen Y, Osika W, Henriksson G, Dahlstrand J, Friberg P (2021) Impact of COVID-19 pandemic on mental health and health behaviors in Swedish adolescents. Scandinavian J Public Health. https://doi.org/10.1177/14034948211021724

72. Singh S, Roy D, Sinha K, Parveen S, Sharma G, Joshi G (2020) Impact of COVID-19 and lockdown on mental health of children and adolescents: a narrative review with recommendations. Psychiatry Res 293:113429. https://doi.org/10.1016/j.psychres.2020. 113429

73. Christakis DA, Van Cleve W, Zimmerman FJ (2020) Estimation of US children's educational attainment and years of life lost associated with primary school closures during the coronavirus disease 2019 pandemic. JAMA Netw Open 3(11):e2028786. https://doi. org/10.1001/jamanetworkopen.2020.28786 